\title{
The effect in sheep of physical form and stage of growth on the sites of digestion of a dried grass
}

\section{Sites of digestion of organic matter, energy and carbohydrate}

\author{
By D. E. BEEVER, * J. F. COELHO dA SILVA, $\uparrow$ \\ J. H. D. PRESCOTT AND D. G. ARMSTRONG \\ Departments of Agricultural Biochemistry and Agriculture, \\ University of Newcastle upon Tyne NEI $7 R U$
}

(Received I3 September I97I - Accepted I8 May I972)

1. The effect of grinding and pelleting artificially dried $\$ 24$ perennial rye-grass (Lolium perenne L.) cut at two stages of maturity on sites of digestion of organic matter, encrgy and carbohydrate were studied in sheep with re-entrant intestinal cannulas fitted at the proximal duodenum and terminal ileum. Chopped and pelleted grasses at both stages of maturity were each given at $900 \mathrm{~g}$ dry matter $/ 24$ h to each of five sheep; the two forms of the early-cut grass were also given at $x 400 \mathrm{~g}$ dry matter/24 h each to four of the five shecp.

2. With the carly-cut grass, grinding and pelleting caused a depression in digestibility of organic matter (low level, $P<0.05$; high level, $P<0.00$ ), lowered the proportion of the digested organic matter disappearing before the small intestine (low level only, $P<0.05$ ) and significantly increased that disappearing in the caccum and colon (low level, $P<0.05$; high level, $P<0.00 \mathrm{I}$ ). Increase in stage of maturity significantly depressed digestibility of orgunic matter $\left(P<{ }^{\circ} 00 x\right.$ ) with both forms of grass and, with the chopped form, significantly increased the proportion of digestible organic matter disappearing in the caecun and colon $(P<0.01)$. Increase in level of feeding of the pelleted, early-cut grass significantly lowered organic matter digestibility $(P<0.05)$, reduced the proportion of digestible organic matter disappearing in the small intestine $(P<0.05)$ and increased that occurring in the caecum and colon $(P<0.05)$.

3. With the early-cut grass, grinding and pelleting caused a depression in digestibility of gross energy only at the higher level of intake $(P<0.01)$, and reduced the proportion of apparently digestible energy disappearing before the small intestine (low level, $P<0.00$; high level, $P<0.05$ ). Only with the chopped form did stage of maturity affect sites of energy digestion; with the more mature grass disappearance of energy in the reticulo-rumen declined $(P<0.01)$ and that in the caecum and colon increased $(P<0.01)$. The effects of level of feeding were similar to those observed for organic matter.

4. With the early-cut grass, and at both levels of intake, digestibilities of cellulose and hemicellulose were depressed by grinding and pelleting $(P<0.00 \mathrm{r})$, as were the proportions of digestible cellulose and hemicellulose disappearing before the small intestine $(P<0.00 \mathrm{r})$. The proportions of these digestible fractions disappearing in the caecum and colon were significantly increased $(P<0 \cdot 00 \mathrm{r})$. Increase in stage of maturity depressed cellulose digestibility $(P<0.00 \mathrm{I}$ ) of the chopped but not pelleted grass and depressed hemicellulose digestibility of both forms $(P<0.00 \mathrm{r})$. The effects of increase in maturity at harvest on sites of digestion depended upon the form of the grass. With the chopped form, as stage of maturity increased, the proportion of digestible hemicellulose disappearing in the reticulo-rumen fell $(P<0.01)$ and that, and the proportion of digestible cellulose, disappearing in the caecum and colon increased ( $P<0.01$ and $P<0.05$ respectively); with the pelleted form, the proportions of digestible cellulose and digestible hemicellulose disappearing in the reticulo-rumen increased $(P<0.001$ and $P<0.01$ respectively) whereas those disappearing in the caecum and colon declined $(P<0.01)$. With the pelleted, early-cut grass increase in intake resulted in a depression in cellulase and hemicellulose digestion $(P<0.05$ and $P<0.00 \mathrm{r}$ respectively) and increased propottional losses of digestible cellulose and digestible homiccllulose in the caecum and colon $(P<0.01$ and $P<0.05$ respectively).

* Present address: Grassland Research Institutc, Hurley, Berkshire.

$\uparrow$ Present address: Department of Zootecnia, Universidade Federal de Viçosa, Viçosa, Minas Gerais, Brazil. 
The benefits to be derived from grinding and pelleting forages in terms of improved animal performance have been well documented (Weir, Meyer, Garrett, Lofgreen \& Ittner, I959; Lloyd, Crampton, Donefer \& Beacom, I960; Minson, 1963; Beardsley, I964; Moore, 1964). With the development of more efficient crop driers, the artificial dehydration of forage crops and packaging of such materials by grinding and pelleting has gained a renewed impetus.

Thomson \& Cammell (I97I) have studied the effects of fincness of grinding and pelleting a dried lucerne on the energy retention of growing lambs given these diets at equals levels of digestible energy intake. Thomson, Beever, Coelho da Silva \& Armstrong (1972) and Coelho da Silva, Seeley, Thomson, Beever \& Armstrong (1972) have examincd the sites of organic matter, energy and carbohydrate digestion and of the nitrogenous constituents in the lucerne diets used by Thomson \& Cammell (r971). The work reported in this paper refers to the sites of digestion in mature sheep of organic matter, energy and carbohydrates contained in an S 24 rye-grass, cut at two stages of maturity and either chopped or ground and pelleted. The same dried-grass diets have also been given to growing lambs in a comparative slaughter trial (Roux, Prescott \& Armstrong, 1970).

\section{EXPERIMENTAL}

Preparation of diets. A primary growth of $\mathrm{S} 24$ rye-grass (Lolium perenne $\mathrm{L}$.) was harvested with a double-chop forage harvester either in mid-May 1968 (designated early-cut) or at the end of June 1968 (medium-cut) and dried immediately in an oilfired, high-temperature, pneumatic, rotary drier (Ford \&Etal Farms Ltd, Northumberland). Each of these two dried grasses was given to sheep either chopped (i.e. as dried grass) or after grinding through a $\mathrm{I}^{\circ} 5 \mathrm{~mm}$ sieve and pelleting.

Sheep. Five mature wether sheep (Suffolk $\times$ Half-bred), 2-3 years old and weighing 45-50 kg, were used. Each sheep was fitted with a rumen cannula, and with re-entrant cannulus at both the proximal duodenum and terminal ileum (Brown, Armstrong \& MacRae, rg68).

Experimental design. Each of the two physical forms of both dried grasses were offered at a controlled level of $900 \mathrm{~g}$ dry matter (DM) $/ 24 \mathrm{~h}$ to the same five sheep. All animals received a particular diet at one time and in the order early-cut chopped, early-cut pelleted, medium-cut chopped, medium-cut pelleted. The two physical forms of the early-cut grass were also given at $\mathrm{I} 400 \mathrm{~g} \mathrm{DM} / 24 \mathrm{~h}$, although to only four of the five sheep due to the accidental loss of one animal; again the feeding of the chopped material preceded that of the pelleted form. It had been intended to give the medium-cut grass at the higher level but owing to large feed refusals this proved to be impossible. It will be realized that since each sheep received the diets in the same order the possibility exists that period effects might have been present.

Management of animals. For details see Beever, Thomson, Pfeffer \& Armstrong (1971).

Collection of samples. Samples of faeces and of duodenal and ileal digesta were collected according to the techniques described by MacRae \& Armstrong (r969) with modifications as outlined by Beever et al. (197I). 
Table I

(a) Composition and physical characteristics of the dried-grass diets

Stage of growth $\ldots$

Physical form...

Organic matter

Total nitrogen

Cellulose

Hemicellulose

Water-soluble carbohydrate

Gross energy (kcal/g DM) $(\mathrm{kJ} / \mathrm{g} \mathrm{DM})$
Early cut

$\begin{array}{cc}\text { Chopped } & \text { Pelleted } \\ 90.9 & 90.6 \\ 3.18 & 3.05 \\ 20.9 & 19.3 \\ 12.6 & 12.3 \\ 14.7 & 14.6 \\ 4.48 & 4.44 \\ 18.8 & 18.6\end{array}$

Medium cut

$\begin{array}{cc}\text { Chopped } & \text { Pelleted } \\ 90.6 & 91.9 \\ 3.15 & 3.03 \\ 26.4 & 25.8 \\ 15.9 & 15.5 \\ 8.9 & 8.8 \\ 4.48 & 4.54 \\ 18.8 & 19.0\end{array}$

(b) Particle size distribution (\% retained in each sieve)

Sieve aperture

$(\mu \mathrm{m})$

$\begin{array}{rr}4760 & 6 \cdot 0 \\ 2400 & 17 \cdot 7 \\ 1200 & 34 \cdot 2 \\ 600 & 32 \cdot 9 \\ 300 & 8 \cdot 3 \\ 150 & 1 \cdot 2 \\ - & 0 \cdot 0 \\ & 3 \cdot 8 \\ & 2: 7: 1\end{array}$

$0 \cdot 0$
$12 \cdot 0$
$11 \cdot 4$
$15 \cdot 3$
$47 \cdot 7$
$13 \cdot 6$
$0 \cdot 0$
$2 \cdot 6$
$1: 3: 6$

$2 \cdot 8$
$\times 3 \cdot 8$
$37 \cdot 9$
$33 \cdot 5$
$9 \cdot 9$
$2 \cdot 0$
0.0
3.6
$2: 7:$

0.0

$0 \cdot 4$

$2 \cdot 1$

$14 \cdot 2$

$43 \cdot 0$ $40 \cdot 2$ 0.0

$\mathrm{I} \cdot 8$

$0: 2: 8$

DM, dry matter.

* Derived from the measurements of particle size distribution by the method of the American Society of Agticultural Engineers ( 1967 ).

Analysis of samples. The accumulated samples of faeces and digesta were thoroughly mixed, subsampled, dried under reduced pressure at $40^{\circ}$ and subsequently ground through a r mm sieve in a Christy \& Norris hammer mill. Representative samples of the foods, obtained during the weighing out of the diets, were similarly ground.

For details of the analytical methods used in the determination of organic matter, gross energy, chromic oxide and cellulose, see Thomson et al. (1972); for the determination of total water-soluble carbohydrate and hemicellulose, see Beever et al. (1971). Particle size distribution measurements, expressed as moduli of fineness (MF) and of uniformity (MU) were made on the foods by the method of the American Society of Agricultural Engineers (1967).

Statistical analysis. It has been noted that only four of the five sheep received the chopped and the pelleted early-cut grass at the higher level of intake. Accordingly, in the factorial method adopted for the statistical analysis of the results (Snedecor, 1956) a missing value was computed for each of these diets. The interaction between factors was statistically significant in almost all analyses; therefore results are discussed as comparisons between six treatments, and not in terms of main effects of factors. 
Table 2. Mean quantities of organic matter present in the food, entering and leaving the small intestine and in the faeces of sheep given dried grass diets. At the low level of intake each diet was given to five sheep, at the high level to four. Mean values for the disappearance of apparently digested organic matter before and in the small intestine and in the caecum and colon are also given

(The values for digesta at the duodenum and ileum ha been adjusted for $100 \%$ recovery of chromic oxide)

\begin{tabular}{|c|c|c|c|c|c|c|c|}
\hline \multirow{3}{*}{$\begin{array}{l}\text { Level of DM intake } \ldots \\
\text { Stage of growth } \ldots \\
\text { Physical form } \ldots\end{array}$} & \multicolumn{4}{|c|}{ Low } & \multirow{2}{*}{\multicolumn{2}{|c|}{$\begin{array}{l}\text { High* } \\
\text { Early cut }\end{array}$}} & \multirow[b]{3}{*}{ SEMt } \\
\hline & \multicolumn{2}{|c|}{ Early cut } & \multicolumn{2}{|c|}{ Medium cut } & & & \\
\hline & Chopped & Pelleted & Chopped & Pelleted & Chopped & Pelleted & \\
\hline \multicolumn{8}{|l|}{ Organic matter $(\mathrm{g} / 24 \mathrm{~h}):$} \\
\hline In food & 819.9 & $853 \cdot 9$ & $775^{\circ} \circ$ & $807 \cdot 9$ & $1286 \cdot 3$ & $I 29 I \cdot I$ & - \\
\hline At proximal duodenum & $366 \cdot 2$ & $46_{5} \cdot 1$ & $429 \cdot 9$ & $467 \cdot 1$ & $622 \cdot 7$ & $712 \cdot 4$ & $\mathrm{I} 2 \cdot \mathrm{I}$ \\
\hline At terminal ileum & 165.2 & $231 \cdot 8$ & 2823 & $27 I \cdot 9$ & $272 \cdot 5$ & $449 \cdot 6$ & $9 \cdot 7$ \\
\hline In faeces & I $36 \cdot 6$ & $162 \cdot 2$ & $206 \cdot 2$ & $206 \cdot 5$ & $214 \cdot 6$ & $280 \cdot 3$ & $6 \cdot I$ \\
\hline $\begin{array}{l}\text { Apparent digestibility } \\
\text { of organic matter }(\%)\end{array}$ & $83 \cdot 3$ & $8 r \cdot 0$ & $73 \cdot 4$ & $74 \cdot 4$ & $83 \cdot 3$ & $78 \cdot \mathbf{I}$ & 0.6 \\
\hline \multicolumn{8}{|c|}{ Disappearance of apparently digested organic matter $(\%)$ : } \\
\hline Before small intestine & 64.4 & $56 \cdot 2$ & $60 \cdot 3$ & $56 \cdot 7$ & $6 I \cdot 9$ & $57 \cdot 3$ & $1 \cdot 5$ \\
\hline In small intestine & 29.4 & 337 & $26 \cdot 3$ & $32 \cdot 5$ & $32 \cdot 7$ & $26 \cdot 0$ & $\mathbf{I} \cdot 8$ \\
\hline In caecum and colon & $4 \cdot 2$ & IO $\cdot 1$ & 13.4 & 10.8 & $5 \cdot 4$ & $16 \cdot 7$ & $\mathbf{I} \cdot 4$ \\
\hline
\end{tabular}

\section{RESULTS}

Table I shows the chemical and physical characteristics of the diets offered. Stage of maturity at harvest is reflected in differences in water-soluble carbohydrate, cellulose and hemicellulose contents but not in total nitrogen content. As might be expected, only small differences in chemical composition were observed with change in physical form. The MF and MU indicate considerable differences between the chopped and pelleted forms of both grasses. The significance of these terms in relation to particle-size distribution has been commented upon by Thomson et al. (1972). Grinding of the early-cut grass through the $\mathrm{x} \cdot 56 \mathrm{~mm}$ sieve and pelleting has reduced the MU value from 3.8 to 2.6 and increased the proportion of fine particles from one to six, out of a total of ten (see MU values, Table 1 ). Grinding of the medium-cut grass has been slightly more effective in reducing particle size; thus the MF value was reduced from 3.6 to $1 \cdot 8$ whereas the number of fine particles in ten increased from one to eight.

Results relating to the digestion of organic matter are shown in Table 2. Grinding and pelleting of the early-cut grass caused a significant reduction in apparent digestibility of organic matter (low level, $P<0.05$; high level, $P<0.001$ ). Organic-matter digestibility fell with increasing maturity at harvest $(P<0.001)$. Increased level of feeding of pelleted early-cut grass significantly reduced digestibility $(P<0.05)$. 
Vol. 28

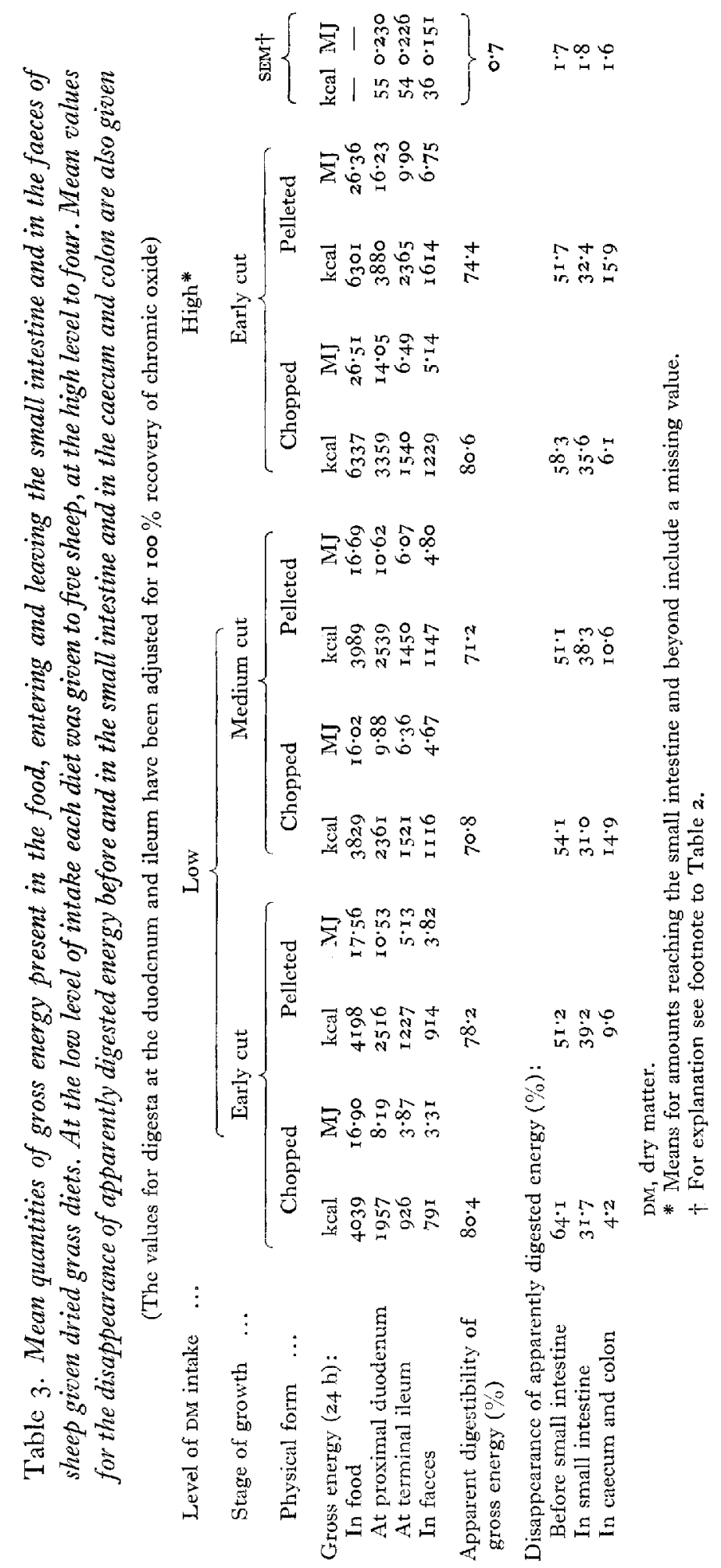


Table 4. Mean quantities of cellulose present in the food entering and leaving the small intestine and in the faeces of sheep given dried grass diets. At the low level of intake each diet was given to five sheep, at the high level to four. Mean values for the disappearance of apparently digested cellulose before and in the small intestine and in the caecum and colon are also given

(The values for digesta at the duodenum and ileum have been adjusted for roo\% recovery of chromic oxide)

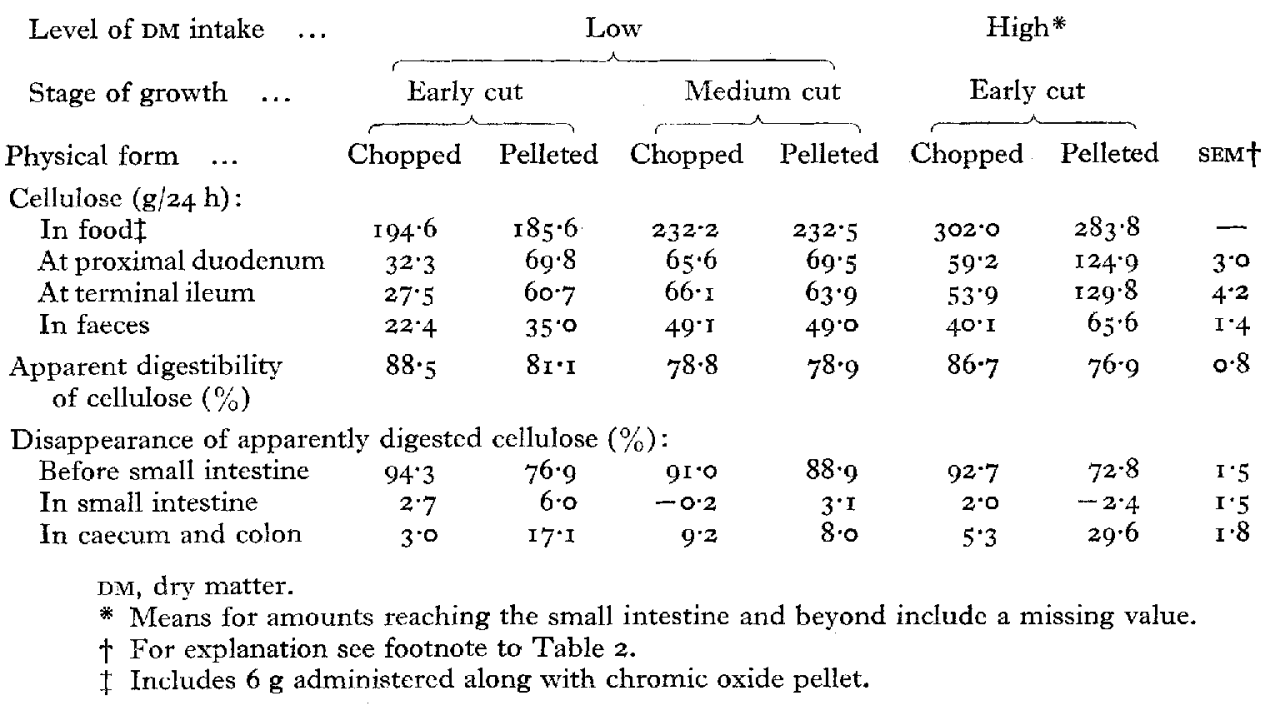

With the early-cut grass, grinding and pelleting reduced the proportion of apparently digestible organic matter (DOM) disappearing before the small intestine when it was given at the low level $(P<0.01)$, and significantly increased that disappearing in the caecum and colon at both levels of intake (low level, $P<0.05$; high level, $P<0.01$ ). With the medium-cut grass, grinding and pelleting significantly increased the proportion of DOM disappearing in the small intestine $(P<0.05)$.

From the results obtained at the low level of intake it can be seen that stage of maturity significantly affected the proportion of DOM lost in the caecum and colon when the chopped grass was given $(P<0.01)$. Concerning level of fecding the only significant differences were with the pelleted grass. At the higher level of feed a smaller proportion of DOM disappeared in the small intestine $(P<0.05)$ and a greater proportion in the caecum and colon $(P<0.05)$ than was so with the low level of feeding.

Values relating to the digestion of gross energy are given in Table 3 . As was to be expected from the values for organic matter, grinding and pelleting of the early-cut grass reduced apparent digcstibility although the effect was only significant at the higher level of intake $(P<0.01)$. Increase in stage of maturity depressed digestibility $(P<0.001)$. For the early-cut grass increase in intake of the pelleted form resulted in a decline in digestibility $(P<0.01)$.

Grinding and pelleting of the early-cut grass reduced the proportion of apparently digestible energy disappearing before the small intestine (low level, $P<0.00 \mathrm{r}$; high 
Table 5. Mean quantities of hemicellulose present in the food, entering and leaving the small intestine and in the faeces of sheep given dried grass diets. At the low level of intake each diet was given to five sheep, at the high level to four. Mean values for the disappearance of apparently digested hemicellulose before and in the small intestine and in the caecum and colon are also given

(The values for digesta at the duodenum and ileum have been adjusted for $100 \%$ recovery of chromic oxide)

\begin{tabular}{|c|c|c|c|c|c|c|c|}
\hline \multirow{3}{*}{$\begin{array}{l}\text { Level of DM intake } \ldots \\
\text { Stage of growth } \\
\text { Physical form } \ldots\end{array}$} & \multicolumn{4}{|c|}{ Low } & \multirow{2}{*}{\multicolumn{2}{|c|}{$\begin{array}{l}\text { High* } \\
\text { Early cut }\end{array}$}} & \multirow[b]{3}{*}{ SEM† } \\
\hline & \multicolumn{2}{|c|}{ Early cut } & \multicolumn{2}{|c|}{ Medium cut } & & & \\
\hline & Chopped & Pelleted & Chopped & Pelleted & Chopped & Pelleted & \\
\hline \multicolumn{8}{|l|}{ Hemicellulose $(g / 24 h)$ : } \\
\hline In food & I I I I I & I I 5.9 & 135.5 & I35.9 & $183 \cdot x$ & $175 \cdot 2$ & - \\
\hline At proximal duodenum & $25 \cdot 7$ & $54 \cdot 2$ & $57 \cdot 5$ & $57 \cdot 2$ & $54 \cdot 3$ & $91 \cdot 8$ & $\mathrm{I} \cdot 8$ \\
\hline At terminal ileum & $24 \cdot 6$ & $46 \cdot I$ & $59^{\circ} \mathrm{I}$ & $52 \cdot 7$ & $42 \cdot x$ & $90 \cdot \mathrm{r}$ & $x \cdot 9$ \\
\hline In faeces & $17^{2} 2$ & $24^{\circ} 9$ & $40 \cdot 0$ & $38 \cdot 5$ & $28 \cdot 8$ & $46 \cdot 8$ & $1 \cdot 2$ \\
\hline $\begin{array}{l}\text { Apparent digestibility } \\
\text { of hemicellulose }(\%)\end{array}$ & $84 \cdot 5$ & $78 \cdot 5$ & $70 \cdot 5$ & $71 \cdot 7$ & $84 \cdot 3$ & $73 \cdot 3$ & 0.6 \\
\hline \multicolumn{8}{|c|}{ Disappearance of apparently digested hemicellulose $(\%)$ : } \\
\hline Before small intestine & $9 \mathrm{r} \cdot 3$ & $68 \cdot 0$ & $81 \cdot 7$ & $80 \cdot 9$ & $84 \cdot 5$ & $65 \cdot 0$ & $I \cdot 9$ \\
\hline In small intestine & 0.8 & 8.8 & $-\mathrm{I} \cdot 6$ & $4 \cdot 6$ & $7 \cdot 8$ & $\mathrm{I} \cdot 4$ & $1 \cdot 5$ \\
\hline In caecum and colon & $7 \cdot 9$ & $23 \cdot 2$ & $20 \cdot 1$ & 14.5 & $8 \cdot 7$ & $33 \cdot 6$ & $\mathrm{I} \cdot 8$ \\
\hline
\end{tabular}

level, $P<0.05$ ), and increased that occurring in the caecum and colon (both levels, $P<0.05$ ). At the low level of intake, grinding and pelleting of both grasses increased the proportion of apparently digestible energy disappearing in the small intestine $(P<0.05)$. With the chopped material, increase in stage of maturity resulted in a significant reduction $(P<0.01)$ in the proportionate loss of apparently digestible energy before the small intestine and significant increase $(P<0.01)$ in that occurring in the caecum and colon. No such effect was noted for the ground and pelleted forms. The only significant effects attributable to level of feeding were with the pelleted grass; proportionate losses of apparently digestible energy were lower in the small intestine $(P<0.05)$ and greater in the caecum and colon $(P<0.05)$ at the higher level of feeding.

The intake of water-soluble carbohydrate fraction ranged from 76 to $21 \mathrm{I} \mathrm{g/24} \mathrm{h}$. In all instances the amounts reaching the proximal duodenum were less than $2.5 \mathrm{~g} / 24 \mathrm{~h}$ and none was detected in the ileal digesta or faecal samples.

The quantities of cellulose in the food, entering and leaving the small intestine and in the faeces are shown in Table 4. Pelleting caused a depression in apparent digestibility of cellulose with the early-cut grass at either level of intake $(P<0.001)$. Increase in stage of maturity significantly depressed cellulose digestibility $(P<0.001)$ for the chopped but not for the pelleted grass. The higher level of intake of the pelleted grass resulted in a significant depression in cellulose digestibility $(P<0.05)$. 
With the early-cut grass, grinding and pelleting significantly reduced the proportionate loss of digestible cellulose before the small intestine (both levels, $P<0.001$ ), and significantly increased that occurring in the caccum and colon (both levels, $P<0.001$ ). The effect of increase in stage of maturity at cutting on the chopped material was to increase the proportionate loss of digestible cellulose in the caecum and colon $(P<0.05)$; with the pellcted grass the effect was to increase the proportionate loss in the reticulo-rumen $(P<0 \cdot 001)$ and decrease that occurring in the caecum and colon $(P<0.01)$. Increase in level of intake of the pelleted, early-cut grass led to a significant increase in cellulose digestion within the caecum and colon $(P<0.01)$.

The fate of the hemicellulose fraction is shown in Table 5 , from which it can be seen that grinding and pelleting of the early-cut grass significantly depresscd digestibility (both levels, $P<0.001$ ). Increase in stage of maturity depressed hemicellulose digestibility with both forms of grass $(P<0.001)$. Digestibility was also depressed at the higher level of intake of the pelleted early-cut grass $(P<0.001)$.

The sites of hemicellulose digestion were very similar to those already described for the cellulose fraction and were affected in an almost identical manner by the various treatments. Thus with the carly-cut grass, grinding and pelleting significantly reduced the proportion of digestible hemicellulose disappearing within the reticulorumen (both levels, $P<0.001$ ) and significantly increased that occurring in the caecum and colon (both levels, $P<0.00 \mathrm{I}$ ). With the chopped grass the effect of stage of maturity at cutting was to decrease the proportional digestion of hemicellulose in the reticulo-rumen $(P<0.01)$ and increase it in the caecum and colon $(P<0.01)$; with the pelleted grass the effect of increase in maturity of the grass at cutting was to increase digestion in the reticulo-rumen $(P<0 \cdot 0 \mathrm{r})$ and decrease the extent of digestion in the caecum and colon $(P<0.01)$. Increasing the amount of pelleted early-cut grass offered led to a significant increase in hemicellulose digestion in the caecum and colon $(P<0.05)$.

\section{DISCUSSION}

It is clear from the results obtained with the dried early-cut $\mathrm{S} 24$ rye-grass given to the sheep that grinding and pelleting induced considerable changes in the sites of digestion of organic matter, energy and carbohydrate. The proportions of apparently digested energy and particularly of the digested structural carbohydrates disappearing before the small intestine were significantly reduced when the chopped grass was replaced by the ground and pelleted grass, whereas the amounts disappearing within the caecum and colon were significantly increased. Similar findings have been reported by Thomson $e t a l$. (1972) for a dried lucerne given to sheep. The extent of ruminal digestion is a function of both rumen retention time and rate of fermentation. Unfortunately, neither of these measurements was made in the present study. Blaxter, Graham \& Wainman (1956) and Rodrigue \& Allen (1960) have, however, reported a reduced rumen retention time when a forage diet is finely ground.

No such effects of grinding and peileting were noted for the medium-cut grass in this study and from information now available it is difficult to account for this. Cer- 
tainly, the differences in behaviour of the two grasses in response to grinding and pelleting do not appear to be explainable on the basis of physical structure. The MF and MU values for the chopped and pelleted forms of the two grasses (see Table I) indicate that with the medium-cut grass there was a greater contrast in particle size between the chopped and pelleted forms than occurred in the early-cut grass. On the basis of a reduced rumen retention time for finely ground particles (see above), one might therefore have expected an even greater contrast in sites of digestion between the chopped and pelleted forms of the medium-cut grass than was seen with the two forms of the early-cut material. It was noticeable that the early-cut grass yielded hard pellets whereas the medium-cut material gave rise to pellets that were extremely friable, this effect being possibly associated with differences in water-soluble carbohydrate content. It may be that the more friable pellets of the medium-cut material allowed an increase in rate of fermentation, thereby minimizing the significance of the cffect that physical form has on mean retention time.

The results of the present study with the early-cut grass show that, when the level of food intake of the chopped material increased from 900 to $1400 \mathrm{~g} \mathrm{DM} / 24 \mathrm{~h}$, there was relatively little effect on the apparent digestibility of organic matter, energy or structural carbohydrates or on their sites of digestion. However, when the material was given in the ground and pelleted form, digestibilities of these fell with higher level of intake, and the contribution of digestion in the caccum and colon appreciably increased. Thus some 30 and $34 \%$ respectively of the digestible fractions of cellulose and hemicellulose were lost in the caecum and colon at the high level of feeding compared with 17 and $23 \%$ respectively at the low level. Campling \& Freer ( 1966 ), in experiments with long, or ground, dried grass given to cows at controlled intake or ad lib., showed increase in level of feeding to depress digestibilities of organic matter and crude fibre only on the ground form. They also found that the high level of feeding with the ground grass caused a marked reduction in the proportionate loss of digestible crude fibre within the reticulo-rumen, and an associated increase in the contribution of the caecum and colon. No such change was observed when the same grass was given in the long form at the high level of intake.

From Table 3 it can be secn that for the two levels of feeding with the chopped and pelleted early-cut grass, despite comparable mean intake (chopped, 5 I $88 \mathrm{kcal}(2 \mathrm{I} / \mathrm{I}$ MJ)/24 h; pelleted $5250 \mathrm{kcal}(2 \mathrm{I} \cdot 97 \mathrm{MJ}) / 24 \mathrm{~h})$, an additional $540 \mathrm{kcal}(2 \cdot 26 \mathrm{MJ}) / 24 \mathrm{~h}$ (mean value) entered the small intestine on the pelleted diets compared with the chopped diets. It is of interest to calculate to what extent this increased entry of gross energy into the small intestine when the early-cut grass is given ground and pelleted can be accounted for in terms of an increased passage of structural carbohydrates into the small intestine. If the energy value of cellulose and hemicellulose is assumed to be the same $(4.18 \mathrm{kcal}(17.5 \mathrm{~kJ}) / \mathrm{g})$, then the extra mean quantities of cellulose $(52 \mathrm{~g} / 24 \mathrm{~h})$ and hemicellulose $(33 \mathrm{~g} / 24 \mathrm{~h})$ entering the small intestine on the two pelleted early-cut grass diets are equivalent to $66 \%$ of the extra energy noted at this section of the tract. Similar calculations for the values relating to a dried lucerne given by Thomson et al. (I972) revealed a value of $70 \%$.

It has already been noted that, when the early-cut grass was pelleted and given at the 
high level of intake, some $30 \%$ of the digestible cellulose and $34 \%$ of the digestible hemicellulose disappeared in passage of the digesta through the caecum and colon. Such results as these and those of Thomson et al. (1972) clearly show the importance of the caecum and colon to total digestion in the sheep and indicate the need for studies to assess the contribution of end-products of digestion arising there to the total supply of absorbed nutrients available within the body.

The authors would like to record their thanks to Mr G. F. Brown MRCVS for veterinary supervision of the sheep, to Mrs M. McDonald for assistance in their routine care and feeding, and to Miss B. Lumsden for analytical assistance. They would also like to thank B. P. (Trading) Ltd for financial support.

\section{REFERENCES}

American Society of Agricultural Engineers (1967). Yb. Am. Soc. agric. Engrs p. 301 .

Beardsley, R. W. (1964). F. Anim. Sci. 23, 239.

Bcever, D. E., Thomson, D. J., Pfeffer, E. \& Armstrong, D. G. (1971). Br. J. Nutr. 26, 123.

Blaxter, K. L., Graham, N. McC. \& Wainman, F. W. (1956). Br. F. Nutr. ro, 69.

Brown, G. F., Armstrong, D. G. \& MacRae, J. C. (1968). Br, vet. F. 124, $7^{8 .}$

Campling, R. C. \& Freer, M. (1 966). Br. \%. Nutr. 20, 229.

Coelho da Silva, F. J., Secley, R. C., Thomson, D. J., Beever, D. E. \& Armstrong, D. G. (1972). Br. F. Nutr. 28, 43 .

Lloyd, L. E., Crampton, E. W., Donefer, E. \& Beacom, S. E. (1960). F. Anim. Sci. I9, 859.

MacRae, J. C. \& Armstrong, D. G. (I 969). Br. J. Nutr. 23, I 5.

Minson, D. J. (1963). F. Br. Grassld Soc. 18, 39.

Moore, L. A. (1964). F. Anim. Sci. 23, 230.

Rodrigue, C. B. \& Allen, N. N. (1960). Can. F. Anim. Sci. 40, 23.

Roux, H. F., Prescott, J. H. D. \& Armstrong, D. G. (1970). Anim. Prod. 12, 370.

Snedecor, G. W. (1 956). Statistical Methods 5 th ed. Ames, Iowa: Iowa State College Press.

Thomson, D. J., Beever, D. E., Coelho da Silva, J. F. \& Armstrong, D. G. (1972). Br. F. Nutr. 28,3 r.

Thomson, D. J. \& Cammell, S. B. (1971). Proc. Nutr. Soc. 3x, 88 A.

Weir, W. C., Meyer, J. H., Garrett, W. N., Lofgreen, G. P. \& Ittner, N. R. (1959). F. Anim. Sci. r8, 805 . 